\title{
Nonprojectile penetrating iron rod from the oral cavity to the posterior cranial fossa: a case report and review of literature
}

This article was published in the following Dove Press journal: International Medical Case Reports Journal

\author{
Zhi Gang Lan' \\ Seidu A Richard ${ }^{1-3}$ \\ Jin $\mathrm{Li}^{\prime}$ \\ Chaohua Yang' \\ 'Department of Neurosurgery, West \\ China Hospital, Sichuan University, \\ Chengdu, Sichuan, People's Republic \\ of China; ${ }^{2}$ Department of Immunology, \\ Jiangsu University, Zhenjiang, \\ Jiangsu, People's Republic of China; \\ ${ }^{3}$ Department of Surgery, Volta \\ Regional Hospital, Ho, Ghana, West \\ Africa
}

\begin{abstract}
Introduction: Nonprojectile penetrating skull base injuries as a result of falls have rarely been confronted in normal neurosurgery although a few nonmissile injuries have been reported. These kinds of injuries represent a life-threatening emergency.

Case presentation: We present an unusual case of a 25 -year-old male construction worker who suffered an accidental penetrating skull base injury when he fell on a metal rod while he was walking on a 2-meter-high platform. He was clinically stable at presentation. Skull radiograph showed a solid metallic bar, $30 \mathrm{~cm}$ long, that penetrated through the right anguli oris eminence and was lodged low in the right occipital bone.

Conclusion: Penetrating injury to the head is considered a form of severe traumatic brain injury. Although case of penetrating head injuries as a result of fall from heights are very rare, we anticipate the construction works on high-rise buildings are at maximum risk. We advise that removal of this kind of foreign bodies be done in the theater and not outside because of risk of involvement of larger vessels leading to fatal hemorrhage. We further suggest that patients with nonprojectile injuries should undergo a preoperative computed tomography-angiography to rule out any vascular injury.
\end{abstract}

Keywords: nonprojectile, fall, hemorrhage, skull, penetrating injury, construction

\section{Introduction}

Penetrating head injury arises when a projectile or nonprojectile object breaks through the cranium and its contents. ${ }^{1-5}$ They are relatively unusual wounds that constitute about only $0.4 \%$ of all head injuries. ${ }^{2}$ These kinds of injuries usually occur as a result of gunshot, missiles or nonmissiles, or wooden or metal objects leading to closed or open wounds, although motor vehicle accidents or occupational accidents and suicidal attempts may also occur., ${ }^{3,5,6}$

Whereas majority of penetrating injuries in western countries occurs as a result of gunshot wounds, surprisingly, this is completely different in developing and third-world countries. There are a wide range of nonmissile or nonprojectile penetrating injuries that have been reported, with weapons such as knifes, scissors, pencils, iron rods, nails, chopsticks, etc. Wounds resulting from these kinds of objects usually involve a smaller area with relatively low-velocity impact. ${ }^{2,3,7}$ It must be recounted that most penetrating skull injuries occurring as a result of nonmissile or nonprojectile objects are rarely associated with major neurological symptoms regardless of the size of the penetrating bodies, except in high-velocity injuries where large amount of kinetic energy, contact with the skull, and the force acting for a shorter time probably cause local deformation
Correspondence: Chaohua Yang Department of Neurosurgery, PostGraduate Training Center, West China Hospital, Sichuan University, 37 Guo Xue Xiang Road, Chengdu, Sichuan 61004I, People's Republic of China

Tel +86 I89 8060 I975

Fax +862885422 490

Email neurovip@yeah.net 
resulting in penetration and skull fracture. ${ }^{2,8,9}$ We present a case of a patient presenting with a penetrating iron rod from the maxillary to the posterior cranial fossa.

\section{Clinical report}

A 25-year-old construction worker suffered an accidental traumatic posterior cranial fossa injury after falling upon a metal rod while he was walking on a 2-meter-high platform. ${ }^{10}$ On arrival at our department, he was alert and cooperative (Glasgow coma scale (GCS) score 15) (Figure 1A). There were no abnormal findings on neurologic exams. Skull radiographs showed that a solid metallic bar, $30 \mathrm{~cm}$ long, had penetrated through the right anguli oris eminence and was lodged low in the right occipital bone ${ }^{10}$ (Figure 1B and C). The extent of structural damage could not be ascertained on the computed tomography (CT) scans as a consequence of severe artifacts associated with the metal $\operatorname{bar}^{10}$ (Figure 1D). CT angiography

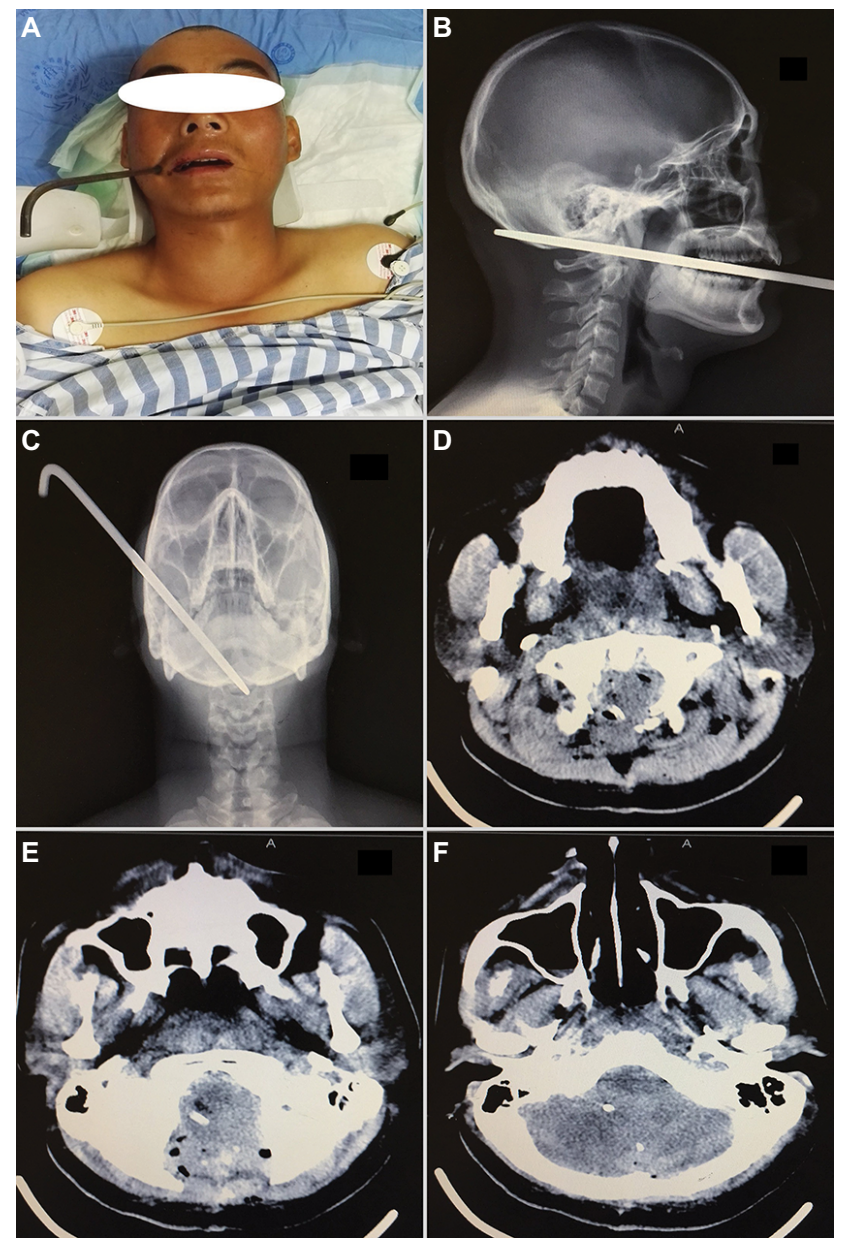

Figure I Preoperative images (A-D) showing the iron rod both in the patient and on imaging studies. (E and $\mathbf{F}$ ) are postoperative $\mathrm{CT}$ scan images.

Note: Modified with permission from Huang J, Li D, Chen H. Successful management of a penetrating ironrod injury through the oral cavity involving the posterior cranial fossa. Neurol India. 2017;65(3):666-668. ${ }^{10}$

Abbreviation: CT, computed tomography.
(CTA) illustrated that the metal rod steered clear of the internal carotid artery and narrowly missed the vertebral artery ${ }^{10}$ (Figure $2 \mathrm{~A}-\mathrm{D})$. We used the rapid sequence intubation to pass the nasotracheal tube. A suboccipital craniotomy was unutilized to remove the rod. The patient was placed in a park-bench position (Figure 3A). A midline incision was made from two fingerbreadths above the inion to the mid-cervical region. After clearance of the musculature, the rod was visualized penetrating through the occipital squama ${ }^{10}$ (Figure 3B). Additional bone removal was achieved by using a high-speed drill and a Kerrison rongeur. The metal rod was further exposed to be going through the dura but left the brain stem alone ${ }^{10}$ (Figure 3C). A steady retraction force was used to pull the rod from the anterior side. Once the rod was clear, thorough hemostasis was achieved by bipolar coagulation. The ipsilateral vertebral artery was revealed to be intact ${ }^{10}$ (Figure 3D). After repeated irrigation with hydrogen peroxide and saline water, the dura was closed in watertight fashion. We kept the patient on ceftriaxone ( 2 g q 8 h) and metronidazole (500 mg q 8 h) for 7 days postoperatively. Postoperative CT scan revealed no hematoma of edema (Figure 1E and F). The patient's postoperative course was uneventful. MRI at the 3-month follow-up showed no abscess formation (Figure 4A and B).

\section{Discussion}

Nonprojectile penetrating skull injuries as a result of fall from heights are very rare and seldom reported in literatures.
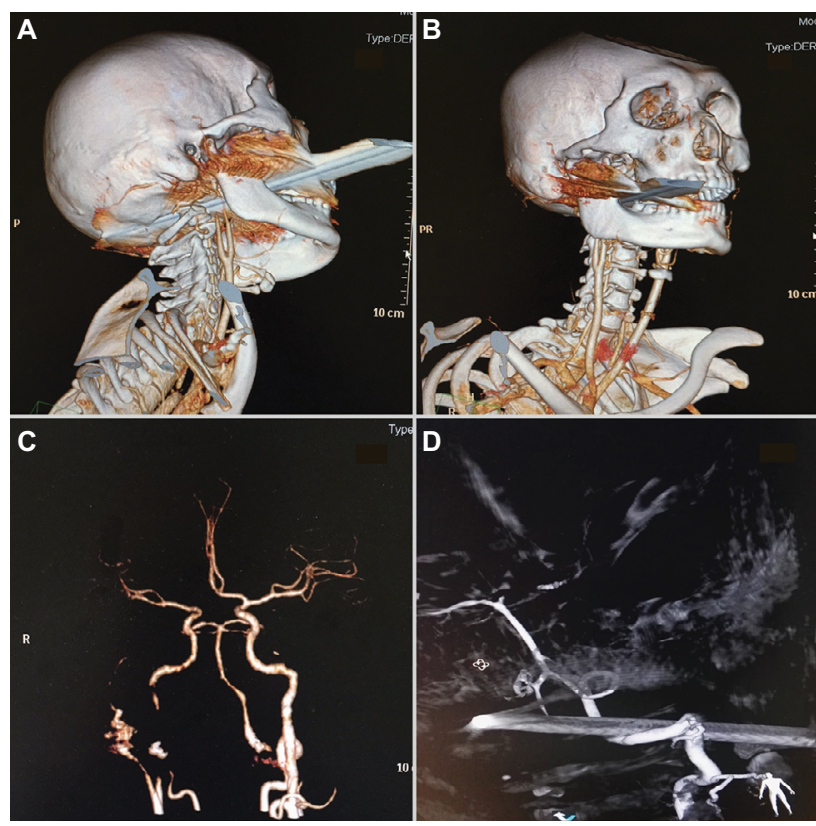

Figure 2 Digital subtraction angiography images showing the iron rod penetrating the bones but narrowly missing the right internal carotid artery (A-D).

Note: Modified with permission from Huang J, Li D, Chen H. Successful management of a penetrating ironrod injury through the oral cavity involving the posterior cranial fossa. Neurol India. 2017;65(3):666-668. ${ }^{10}$ 


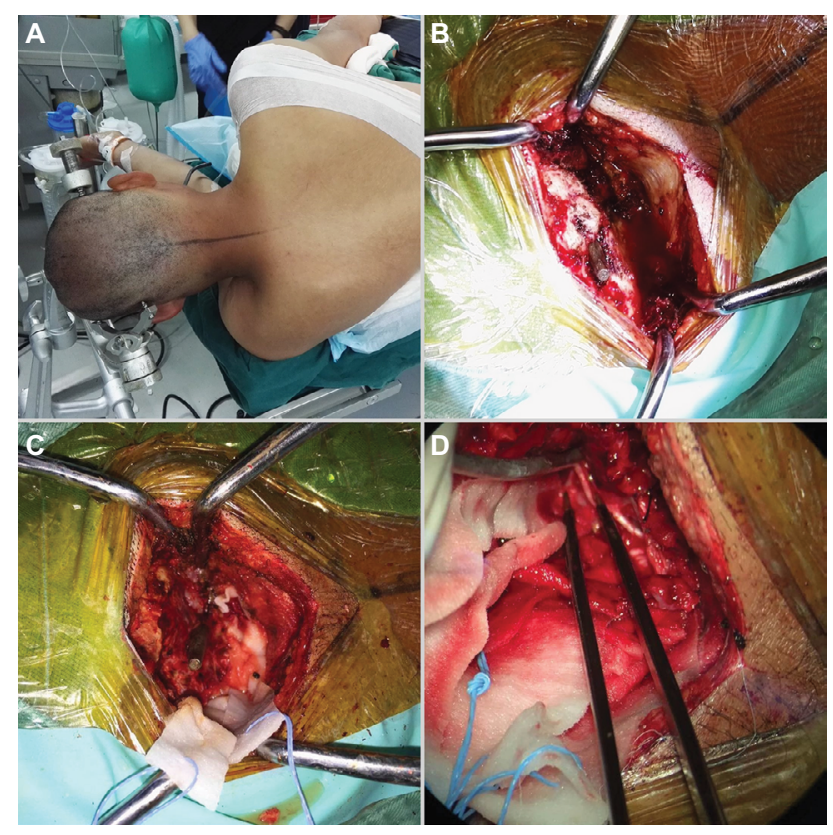

Figure 3 Intraoperative images showing the iron rod lodged in the posterior skull and in the brain tissues (A-D).

Note: Modified with permission from Huang J, Li D, Chen H. Successful management of a penetrating ironrod injury through the oral cavity involving the posterior cranial fossa. Neurol India. 2017;65(3):666-668. ${ }^{10}$
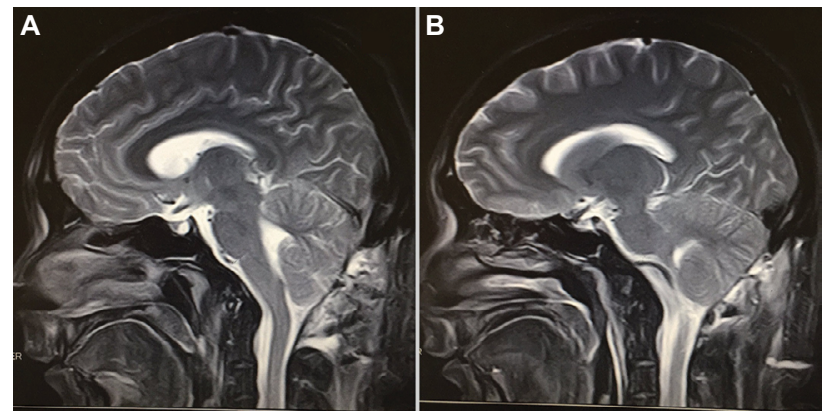

Figure $4 \mathrm{MRI}$ taken during follow-up outpatient visit 3 months after the removal of the iron $\operatorname{rod}(\mathbf{A}$ and $\mathbf{B})$.

A penetrating head injury occurs when the dura mater is breached as a result of either high-velocity objects like bullets and missiles or lower velocity objects such as knife (most common) and rarely nails, keys, pencils, and chopsticks and/ or ${ }^{1,11-14}$ wooden, stony, glassy, and other industrial or environmental objects. ${ }^{3,15-18}$ In most cases, the bone fragments from a skull fracture are driven into the brain. Projectile objects (gunshots or missiles) are associated with high velocity, which makes them cause deep tissue cavitation. Furthermore, temporal cavitation is caused by missiles because tissue elasticity causes the cavity walls to pulsate in a violent waning fashion and eventually collapse, hence the name temporary cavity. ${ }^{19}$ On the other hand, permanent cavitation is caused by penetration injuries, such as in our case, because there is always a formation of a permanent cavity. Their shock waves are the main causes of complex injuries and poor prognosis. ${ }^{3,20}$ Nonprojectiles objects on the other hand usually move with a velocity less than $100 \mathrm{~m} / \mathrm{s}$ and are associated with direct disruption and laceration of tissues. These kinds of forces mainly cause localized primary injury and lead to better prognosis. ${ }^{3,20-22}$ Our case is very unique because the solid metallic bar, $30 \mathrm{~cm}$ long, penetrated through the right anguli oris eminence, through the mylohyoid groove, sparing the right common carotid artery, and finally lodged low in the right occipital bone.

CT scan is the most accepted radiological modality of choice for the evaluation of patients with penetrating skull injuries. Many authors are of the view that patients with penetrating skull injuries should have unenhanced standard axial views with bone and soft tissue windows even with trivial scalp laceration, ${ }^{3}$ and for accurate assessment of the injuries coronal and sagittal sections are very vital. ${ }^{3,23,24}$ On the other hand, most neurosurgeons do not agree with the use of MRI in patients with penetrating skull injuries because it does not give any better visualization of bones and can be potentially dangerous in ferromagnetic objects. ${ }^{3}$ However, patients with nonmetallic penetrating skull injuries can benefit immensely with MRI angiography, if the service is available at the facility they present. We suggest that patients with nonprojectile injuries should undergo a preoperative CTA to rule out any vascular injury.

The targets of surgical intervention in patients with these injuries are to remove the penetrating item from the brain parenchyma, remove necrotic tissue, debris, and other potential contaminants, evacuate any hematomas occurring from the injury, and secure hemostasis as well as ensure watertight closure of the dura to prevent cerebrospinal fluid leakage. ${ }^{5}$ Notwithstanding the presence of well-written guidelines for managing these cases, surgical treatment requires an individualized approach tailored to the situation at hand. ${ }^{3}$ Many authors including us suggest that the foreign body should never be removed outside the theater because of the possibility of injuring larger vessels leading to fatal hemorrhage when the object is forcefully pulled out., ${ }^{3,25}$ The bulging object should also be stabilized during transportation, evaluation, and treatment to prevent further injury. During the operation in the theater, the foreign object should be carefully removed in the direct reverse path of trajectory without swinging movements to prevent further damage., $3,21,26$ The dura should be closed in a watertight manner, either by direct closure or by using autologous grafting materials, eg, pericranium. Synthetic grafts, being a foreign body, become a potential source of infection. ${ }^{3,27,28}$ 
Some of the complications anticipated in the management of these kinds of injuries may be cerebrospinal fluid fistula and neuroendocrine dysfunction. Most deaths from penetrating skull injuries are as a result of damage to larger blood vessels leading to intracranial hematomas and ischemia, which can in turn lead to a biochemical cascade called the ischemic cascade. ${ }^{3}$ Our patient was so fortunate the rod narrowly missed the external carotid artery, as seen in the angiogram (Figure 2D). Many authors with similar experiences have estimated vascular complications arising from penetrating skull injuries to be $5 \%-40 \%$ depending on the type of artery or sinus involve. ${ }^{3,29,30}$ Patients who survive these complication most often develop vasospasm, pseudoor true traumatic aneurysm, arteriovenous malformation, subarachnoid hemorrhage. ${ }^{3}$

Post-traumatic epilepsy is another complication experiences by many authors. ${ }^{1,3,4,29,31,32}$ They pinned direct cortical injury with subsequent scarring as the main cause of seizures after this traumatic event. This occurrence is further classified into immediate ( $<24$ hours), early seizures ( $<1$ week), and late seizures ( $>1$ week). ${ }^{3,31,33}$ Patients with penetrating skull injuries are also highly susceptible to infection, which may aggravate their condition as well as increase their mortality rates. ${ }^{3,34}$ Deep or multifocal brain injury, intracranial retained bone and metallic fragments, cerebrospinal fluid fistulas, air sinus wounds, transventricular injuries, or wounds crossing the midline are but the many possible way patients can develop post-traumatic infection. ${ }^{3,28}$ The most frequently associated organism is Staphylococcus aureus because this organism forms part of the normal flora of the skin and thus gets inoculated into the open wound, ${ }^{3,35}$ leading to scalp sepsis, osteomyelitis, epidural and subdural empyemas, meningitis, ventriculitis, cerebritis, and cerebral abscess. . $^{218}$

Antimicrobial agents have markedly decreased the rate of infections since their introduction. The choice of antimicrobial agents depends on the protocols of the institution or department and the type of organism anticipated. It is also imperative to give antitetanus shots to patients although the incidence of tetanus has reduced. Birch-Hirshfield has indicated in his report that there is about $67 \%$ mortality rate in the patients who developed tetanus infection, thus stressing the importance of tetanus immunization as required. ${ }^{2}$

\section{Conclusion}

Penetrating injury to the head is considered a form of severe traumatic brain injury. Nonprojectile or nonmissile injuries are not uncommon in developing countries, especially in the rural setups and construction sites in the cities. Although cases of penetrating head injuries as a result of fall from heights are very rare, we anticipate the construction workers on high-rise building are at maximum risk. We advise that removal of this kind of foreign bodies be done in the operating room and not out outside because of risk of involvement of larger vessels leading to fatal hemorrhage. We further suggest that patients with nonprojectile injuries should undergo a preoperative CTA to rule out any vascular injury.

\section{Ethics approval and consent to participate}

The ethical committee of West China Hospital fully approved our case study. The patient and his relatives were informed about our intention to involve him in a case study and he/they agreed to partake in the study. He/they signed the consent form before the operation was carried out according to all surgical protocols and consent was also obtained for the case details and accompanying images to be published.

\section{Author contributions}

All authors contributed toward data analysis, drafting and critically revising the paper and agree to be accountable for all aspects of the work.

\section{Disclosure}

The authors report no conflicts of interest in this work.

\section{References}

1. Kothari K, Singh AK, Das S. Penetrating skull injury with six inch fence rod. Natl J Maxillofac Surg. 2012;3(2):207.

2. Arifin MZ, Gill AS, Faried A. Penetrating skull fracture by a wooden object: management dilemmas and literature review. Asian J Neurosurg. 2012;7(3):131.

3. Younes W. Craniocerebral injuries by impacted foreign objects: case series and literature review. Egypt J Neurosurg. 2015;30:55-62.

4. Xu F, Li J, Sun S, et al. The surgical management of a penetrating orbitocranial injury with a Bakelite foreign body reaching the brain stem. Brain Injury. 2013;27(7-8):951-956.

5. Regunath K, Awang S, Siti S, Premananda M, Tan W, Haron R. Penetrating injury to the head: case reviews. Med J Malaysia. 2012;67(6): 622-624.

6. Bhaganagare A, Nadkarni T, Goel A. Penetrating craniocerebral injury with nails: case report. Indian J Neurotrauma. 2007;4(1):63-64.

7. Schaller B. Subcranial approach in the surgical treatment of anterior skull base trauma. Acta Neurochir. 2005;147(4):355-366.

8. Gennarelli TA, Champion HR, Sacco WJ, Copes WS, Alves WM. Mortality of patients with head injury and extracranial injury treated in trauma centers. J Trauma Acute Care Surg. 1989;29(9): 1193-1202.

9. Schaller BJ, Kleindienst A, Kruschat T, Schliephake H, Buchfelder $\mathrm{M}$, Merten HA. Industrial nail gun injury to the anterior skull base: a case report and review of the literature. J Trauma Acute Care Surg. 2008;64(3):E29-E32. 
10. Huang J, Li D, Chen H. Successful management of a penetrating ironrod injury through the oral cavity involving the posterior cranial fossa. Neurol India. 2017;65(3):666-668.

11. Pascual J, Navas M, Carrasco R. Penetrating ballistic-like frontal brain injury caused by a metallic rod. Acta Neurochir. 2009;151(6):689.

12. Salar G, Costella GB, Mottaran R, Mattana M, Gazzola L, Munari M. Multiple craniocerebral injuries from penetrating nails: case illustration. J Neurosurg. 2004;100(5):963.

13. Koestler J, Keshavarz R. Penetrating head injury in children: a case report and review of the literature. J Emerg Med. 2001;21(2):145-150.

14. Herring CJ, Lumsden AB, Tindall SC. Transcranial stab wounds: a report of three cases and suggestions for management. Neurosurgery. 1988;23(5):658-662.

15. Balak N, Aslan B, Serefhan A, Elmaci I. Intracranial retained stone after depressed skull fracture: problems in the initial diagnosis. Am J Forensic Med Pathol. 2009;30(2):198-200.

16. Chibbaro S, Tacconi L. Orbito-cranial injuries caused by penetrating non-missile foreign bodies. Experience with eighteen patients. Acta Neurochir. 2006;148(9):937-942.

17. Gökçek C, Erdem Y, Köktekir E, et al. Intracranial foreign body. Turk Neurosurg. 2007;17(2):121-124.

18. Kazim SF, Bhatti A, Godil SS. Craniocerebral injury by penetration of a T-shaped metallic spanner: a rare presentation. Surg Neurol Int. $2013 ; 4: 2$.

19. Stefanopoulos P, Filippakis K, Soupiou O, Pazarakiotis V. Wound ballistics of firearm-related injuries - Part 1: missile characteristics and mechanisms of soft tissue wounding. Int J Oral Maxillofac Surg 2014;43(12):1445-1458.

20. Jandial R, Reichwage B, Levy M, Duenas V, Sturdivan L. Ballistics for the neurosurgeon. Neurosurgery. 2008;62(2):472-480.

21. Kataria R, Singh D, Chopra S, Sinha V. Low velocity penetrating head injury with impacted foreign bodies in situ. Asian J Neurosurg. 2011;6(1):39.

22. Clark WC, Muhlbauer MS, Watridge CB, Ray MW. Analysis of 76 civilian craniocerebral gunshot wounds. J Neurosurg. 1986;65(1):9-14.

23. Coles J. Imaging after brain injury. Br J Anaesth. 2007;99(1):49-60.
24. Zhang CW, Richard SA, Wu C, Wang T, Lui LX, Xie XD. Successful treatment of iatrogenic vertebral artery pseudoaneurysm with coil embolization: case report. J Vasc Med Surg. 2017;5:342.

25. Schreckinger M, Orringer D, Thompson BG, La Marca F, Sagher O. Transorbital penetrating injury: case series, review of the literature, and proposed management algorithm: report of 4 cases. J Neurosurg. 2011;114(1): 53-61.

26. Prakash Rao G, Rao N, Reddy P. Technique of removal of an impacted sharp object in a penetrating head injury using the lever principle. $\mathrm{Br}$ J Neurosurg. 1998;12(6):569-571.

27. Esposito DP, Walker JB. Contemporary management of penetrating brain injury. Neurosurg Q. 2009;19(4):249-254.

28. Sweeney JM, Lebovitz JJ, Eller JL, Coppens JR, Bucholz RD, Abdulrauf SI. Management of nonmissile penetrating brain injuries: a description of three cases and review of the literature. Skull Base Rep. 2011;1(1):39-46.

29. Nathoo N, Boodhoo H, Nadvi SS, Naidoo SR, Gouws E. Transcranial brainstem stab injuries: a retrospective analysis of 17 patients. Neurosurgery. 2000;47(5):1117-1123.

30. Richard SA, Wu M, Lin D. Traumatic subdural effusion evolving into chronic subdural hematoma. Open J Modern Neurosurg. 2014;5(1):12.

31. Christensen J, Pedersen MG, Pedersen CB, Sidenius P, Olsen J, Vestergaard M. Long-term risk of epilepsy after traumatic brain injury in children and young adults: a population-based cohort study. Lancet. 2009;373(9669):1105-1110.

32. Richard SA, Shrestha SS, Zhang C, et al. Successful treatment of a child with ruptured arteriovenous malformation using onyx embolization: a case report. Open J Modern Neurosurg. 2017;7(4):153.

33. Kharatishvili I, Pitkänen A. Posttraumatic epilepsy. Curr Opin Neurol. 2010;23(2):183-188.

34. Peek-Asa C, McArthur D, Hovda D, Kraus J. Early predictors of mortality in penetrating compared with closed brain injury. Brain Injury 2001;15(9):801-810.

35. Bayston R, De Louvois J, Brown E, Johnston R, Lees P, Pople I. Use of antibiotics in penetrating craniocerebral injuries. Lancet. 2000;355(9217):1813-1817.
International Medical Case Reports Journal

\section{Publish your work in this journal}

The International Medical Case Reports Journal is an international, peer-reviewed open-access journal publishing original case reports from all medical specialties. Previously unpublished medical posters are also accepted relating to any area of clinical or preclinical science. Submissions should not normally exceed 2,000 words or

\section{Dovepress}

4 published pages including figures, diagrams and references. The manuscript management system is completely online and includes a very quick and fair peer-review system, which is all easy to use. Visit http://www.dovepress.com/testimonials.php to read real quotes from published authors. 